\title{
LIFE VITISOM: innovation in viticulture
}

\author{
Paolo Mulotto ${ }^{1 *}$, Isabella Ghiglieno ${ }^{2}$, and Leonardo Valenti ${ }^{1}$ \\ ${ }^{1}$ Università degli Studi di Milano, Dipartimento di Scienze Agrarie ed Ambientali, via Celoria 2, 20133, Milano, Italy \\ ${ }^{2}$ Università degli Studi di Brescia, Dipartimento di ingegneria Civile, Architettura, Territorio, Ambiente e di Matematica Agrofood \\ Lab, Via Branze, 43, 25123, Brescia, Italy
}

\begin{abstract}
Soil organic matter $(\mathrm{SOM})$ is considered a fundamental element for the vitality of agricultural soils. The depletion of SOM is a main concern for grape-growing compartment as the increase of mechanical approach is fastening its degradation. SOM loss in vineyard soils lead to a decrease of yield and quality of products as a consequence of a reduction of soil chemical and biological fertility. In order to contrast SOM erosion, research aiming at finding sustainable management practices are enhancing in agricultural sector. In the present study a three-year research was carried out in vineyard with the aim to compare the application of three different organic fertilizers. The effects of organic fertilisation on vines, grapes and wines were investigated in five different Italian wine-growing areas. The positive effect of organic fertilisation is highlighted, especially in the conservation of acidic content of the must. The effect of fertilization is also revealed in differences in wine aromas at wine tasting.
\end{abstract}

\section{Introduction}

In 2009 the European Union defined soil organic matter (SOM) as the very foundation for healthy soils, highlighting how its erosion causes the degradation of the soil itself.

The importance of SOM content has long been known [1, 2], but it has been further highlighted by the progress in the knowledge about soil composition [3, 4; $5 ; 6,7]$. SOM positive functions lie both in a general improvement of fertility conditions, and in positive effects in soil structure, water retention and nutrients availability. SOM also provides the necessary conditions for the good nutrition of soil organisms $[6 ; 7,8,9,10]$.

In short, SOM is:

- a "source of food" for subterranean fauna and contributes substantially to soil biodiversity;

- the core of soil fertility: organic carbon strengthens soil structure and promotes the penetration of roots into the soil improving the physical environment;

- capable of holding up to six times its weight in water. Soils containing more SOM have a better structure, which helps the infiltration of water and reduces soil susceptibility to compaction, erosion and landslides [11].

Modern viticulture faces growing threats with regard to the depletion of SOM caused by the tendency to establish more and more intensive cultivation systems, with a reduction of planting distances, and by an increased mechanization, which results in the creation of hardpan layers $[12,13]$. These recent tendencies in the use of the soil, together with the effects of climatic change have brought to a loss of organic carbon in the soil across Europe.
In this context research is required aimed at identifying management strategies that allow to preserve and increase the level of SOM in European soils with positive effect on vineyards yield and grapes, musts and wines quality. Previous studies demonstrated that vineyards that grow on soils with a high content of SOM have a higher vigor and a higher vegetative-productive balance due to a major content of nutrients and are less exposed to water stress. Benefits are also reported on must and wine as a higher content of nutrients promotes the growth of the vegetation and a major conservation of wine acidity $[11,14]$.

In the present study results obtained from a threeyear research are reported with the aim to evaluate the effect of the application of three different organic fertilizers on vineyard yield and grapes, musts and wine quality. The research was included in the context of the European Project LIFE VITISOM (LIFE15ENV/IT/000392) which aimed to build an innovative system for the management of the organic fertilization of vineyard, allowing to contrast the depletion of the organic matter and improve the uniformity and quality of soils. Results obtained by this project can be a helpful contribute to demonstrate the importance of organic fertilization in vineyards and can increase the knowledge of the effects of SOM on vine, must and wine quality.

\footnotetext{
*Corresponding author: paolo.mulotto@unimi.it
} 


\section{Materials and Methods}

\subsection{Testing sites}

The experiment was conducted for three years, 20172018-2019. The project involves five wineries located in different parts of Italy; three in the North (Castello Bonomi and Guido Berlucchi in Brescia - Lombardy, Bosco del Merlo in Venice - Veneto), one in the Centre (Premiata Fattoria Castelvecchi in Siena - Tuscany) and one in the South (Conti degli Azzoni in Macerata Marche). For each winery an experimental vineyard was selected; the characteristics of experimental vineyards are reported in table 1 .

Table 1. Experimental vineyards characteristics

\begin{tabular}{|l|l|l|l|}
\hline Winery & Variety & $\begin{array}{l}\text { Density } \\
\text { (plant/Ha) }\end{array}$ & $\begin{array}{l}\text { Training } \\
\text { system }\end{array}$ \\
\hline $\begin{array}{l}\text { Guido } \\
\text { Berlucchi }\end{array}$ & Chardonnay & 10.000 & Guyot \\
\hline $\begin{array}{l}\text { Castello } \\
\text { Bonomi }\end{array}$ & Chardonnay & 6.000 & $\begin{array}{l}\text { Spurred } \\
\text { Cordon }\end{array}$ \\
\hline $\begin{array}{l}\text { Bosco del } \\
\text { Merlo }\end{array}$ & Glera & 5.000 & $\begin{array}{l}\text { Double } \\
\text { Cordon }\end{array}$ \\
\hline $\begin{array}{l}\text { Conti degli } \\
\text { Azzoni }\end{array}$ & $\begin{array}{l}\text { Cabernet } \\
\text { sauvignon }\end{array}$ & 5.000 & Guyot \\
\hline Castelvecchi & Sangiovese & 5.000 & $\begin{array}{l}\text { Spurred } \\
\text { Cordon }\end{array}$ \\
\hline
\end{tabular}

\subsection{Experimental plan}

In each vineyard three different organic fertilizers were applied: compost, solid fraction of digestate and manure. Each treatment was distributed both incorporating the organic fertilization into the soil and leaving it on the surface. Distributions were carried out once per year, in autumn, with the exception of the first year where distribution was carried out in spring. It was also selected an untreated treatment (not fertilized) where the soil was both tilled and not tilled for a total of eight treatments (Table 2).

Table 2. Treatments description and relative code

\begin{tabular}{|c|l|}
\hline CODE & TREATMENT DESCRIPTION \\
\hline TL & Test non fertilized and non-tilled \\
\hline TNL & Test non fertilized but tilled \\
\hline CL & Compost incorporated into the soil \\
\hline CNL & $\begin{array}{l}\text { Compost not incorporated into the } \\
\text { soil }\end{array}$ \\
\hline DL & $\begin{array}{l}\text { Solid fraction of digestate } \\
\text { incorporated into the soil }\end{array}$ \\
\hline DNL & $\begin{array}{l}\text { Solid fraction of digestate not } \\
\text { incorporated into the soil }\end{array}$ \\
\hline LL & Manure incorporated into the soil \\
\hline LNL & $\begin{array}{l}\text { Manure not incorporated into the } \\
\text { soil }\end{array}$ \\
\hline
\end{tabular}

\subsection{In-field data collection}

For each treatment 30 vines divided into 3 replicates (10 vines for each replicates) were selected and for each vine data of weight, number of bunches, number of not sprouted buds and shoots were collected. The selected plants were signed and manually pruned during the winter period. The wood produced in the year was weighted to calculate the Ravaz Index. A total of three bunches per vine were collected and manually pressed. The must was analyzed with Steroglass Flash Automatic Tritator to determinate $\mathrm{pH}$ and titratable acidity $(\mathrm{g} / \mathrm{l})$. Sugar content was measured by a refractometer to obtain the ${ }^{\circ}$ Brix.

\subsection{Wine production}

Sixty kilogrammes of grapes were collected for each treatment to produce micro-vinifications through the application of standardized protocols:

- sparkling wine: after 24 hours storage at $10^{\circ} \mathrm{C}$, $1 \%$ of sulfur dioxide was sprayed on the grapes. Grapes were then pressed with a hydraulic press working at 2 bar to extract $25 \mathrm{~L}$ of must. The extracted must was treated with sulfur dioxide, $2 \mathrm{~g} / \mathrm{hl}$ of pectinase enzyme and $5 \mathrm{~g} / \mathrm{hl}$ of polyvinylpolypyrrolidone (PVPP) and successively stored for 24 hours at $10^{\circ} \mathrm{C}$. Once the must was separated from the solid fraction, it was inoculated with $10 \%$ of yeasts. The fermentation was conducted with a controlled temperature of $12^{\circ} \mathrm{C}$. Pre-bottling clarification was done adding $10 \mathrm{mg} / \mathrm{hl}$ silica sol and 1 $\mathrm{ml} / \mathrm{hl}$ of gelatin. Second fermentation was obtained adding $0,3 \mathrm{~g} / \mathrm{l}$ of yeast and $22 \mathrm{~g} / \mathrm{l}$ of sugar.

- red wine: grapes were treated with $1 \%$ sulfur dioxide, separated from the stalk and pressed; $10 \mathrm{gr} / \mathrm{hl}$ of potassium metabisulfite, $15 \mathrm{~g} / \mathrm{hl}$ of tannin, $30 \mathrm{~g} / \mathrm{hl}$ of yeast nutrient were then added and $40 \mathrm{~g} / \mathrm{hl}$ of yeast were used to start fermentation. Three pump-overs per day were done for the first 4 days; a délestage was carried out at the $2^{\text {nd }}$ day of fermentation with an addition of 10 $\mathrm{g} / \mathrm{hl}$ of ammonium phosphate $(99,88 \%)$ and thiamine. Pumps-overs were then reduced to two until the end of the fermentation. After the fermentation wine was inoculated with malo-lactic bacteria.

Sensory profiles of wines were tasted by a panel of 15 experts using specific descriptors for each wine typology.

\subsection{Statistical Analysis}

All the data were treated with SPSS (Statistical Package for Social Science) software for statistical analysis. In the preliminary data analysis, outliers were deleted; i.e., observations with values greater than 1.5 interquartile ranges (IQRs) above the third quartile, or lower than $1.5 *$ IQRs below the first quartile.

To analyze analytical, growth-productivity and wine tasting results, different ANOVA models $(\mathrm{p}<0.05)$ were performed. Total data were studied considering the different treatments (TL, TNL, CL, CNL, DL, DNL, LL, LNL) for each year and then analyzed for each single 
winery. ANOVA was also carried out comparing both different type of soil management (tilled, not tilled, incorporated, not incorporated) and different type of fertilizer (compost, digestate and manure) in the three year of project. A post-hoc Duncan procedure was implemented to compare the treatment means.

\section{Results and Discussion}

Results are presented showing the comparison among different types of fertilizer (compost, digestate, manure) and the untreated control. The comparison among different type of soil management was reported only in the case of titratable acidity of musts which, however, does not seem to affect significantly the vegetativeproductive and analytical parameters. In case of results obtained from wine tastings, results are reported comparing both the fertilizer used and the type of soil management. Data obtained in 2017 and 2019 are reported with the aim to compare the first and the last year of distribution, as the mineralization of organic matter is a slow process over time and more years should be necessary to see fertilizers effects on plants [15].

\subsection{Vine yield}

No significant differences among treatments are recorded considering the yield per vine, neither comparing the type or fertilizer (compost, digestate and manure) nor comparing soil management (tilled/incorporated - not tilled/not incorporated). There is an increase of production in 2019 respect to 2017 as reported in figure 1 but, as the increase can be seen also in the test, it cannot be considered an effect of fertilizers.

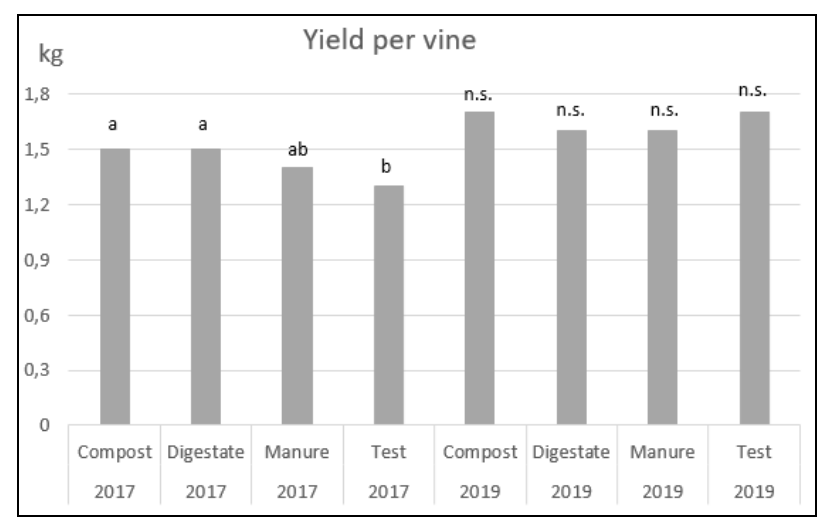

Fig.1 - Yield per vine comparing different type of fertilizers

\subsection{Must quality}

Figure 2 reports the results for titratable acidity for different soils managements; in 2019 the effects of Incorporated - Not incorporated fertilizers did not influence the titratable acidity.

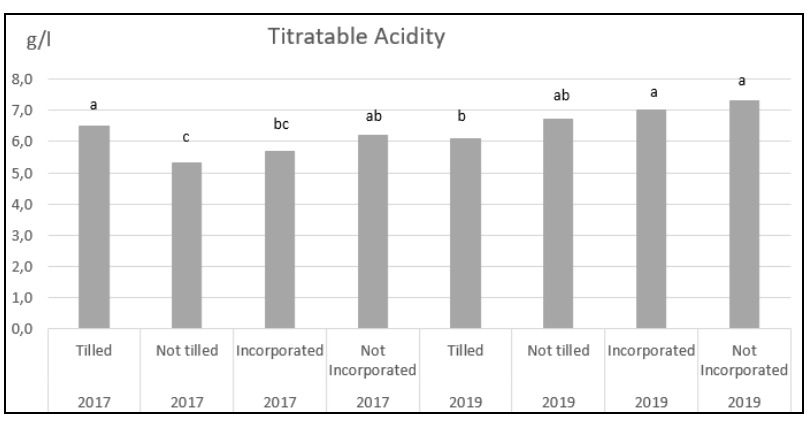

Fig.2. Titratable acidity comparing different soil management

Figure 3 shows results obtained for must titratable acidity comparing different type of fertilizers. An increase of must titratable acidity can be highlighted comparing the untreated test and the three fertilized treatments in 2019. This response could be related to the effects of fertilizers promoting the conservation of the acidity as reported in previous studies $[14,16]$.

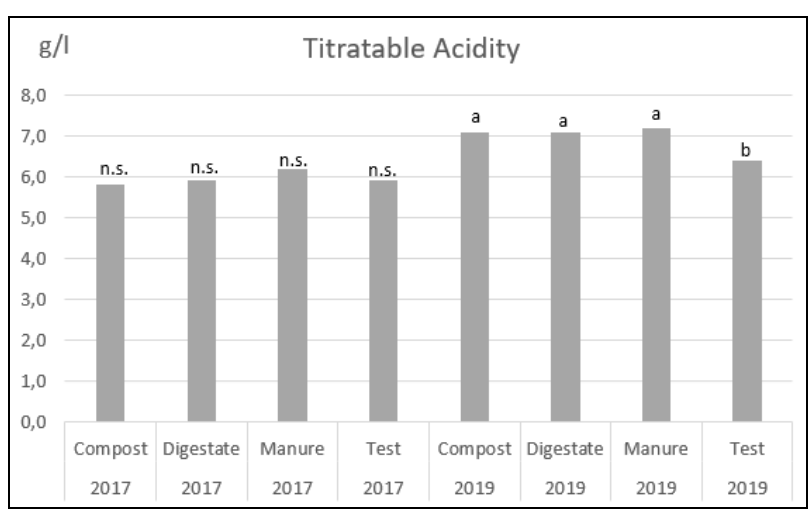

Fig.3. Titratable acidity comparing different type of fertilizers

Titratable acidity is a characteristic of primary importance in determining sparkling wine quality, where the acidity is the basis for the longevity of the final product. Guido Berlucchi and Castello Bonomi are located in the Franciacorta wine growing area, the most famous Italian viticultural Region for sparkling wine production. Results obtained in must titratable acidity of these wineries are presented in Figure 4 and 5.

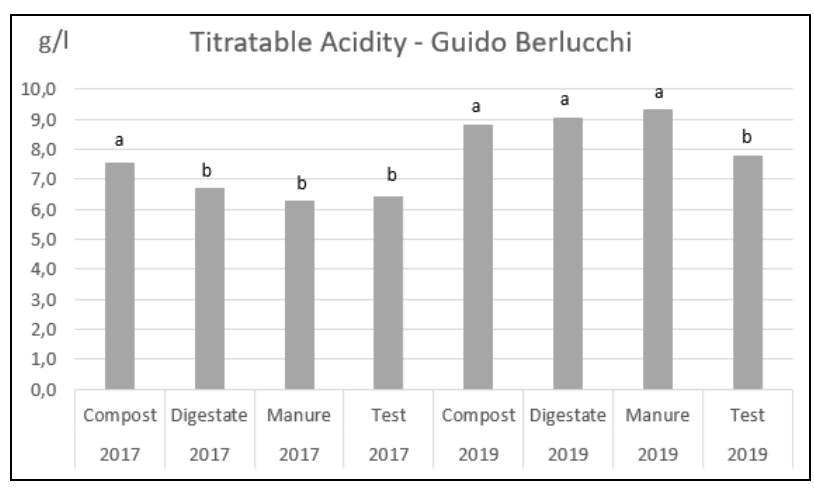

Fig.4. Titratable acidity comparing different type of fertilizers Guido Berlucchi winery 


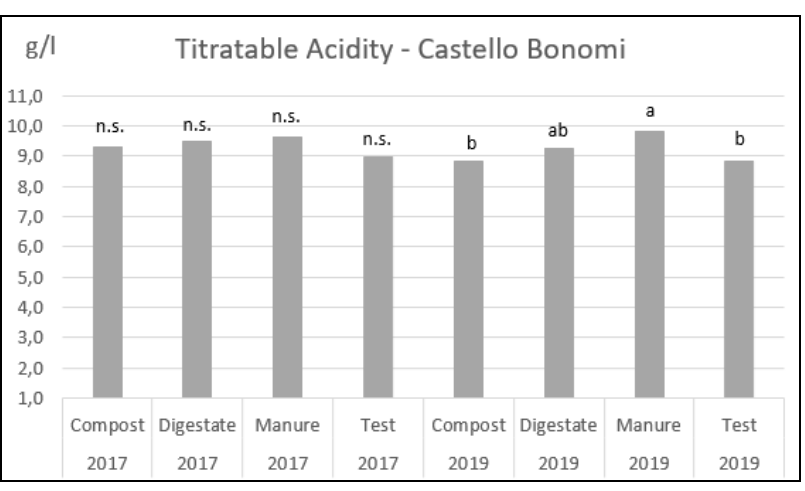

Fig.5. Titratable acidity comparing different type of fertilizers Castello Bonomi winery

As reported both Figure 4 and 5, the higher content of titratable acidity is obtained in case of organic fertilizers application. The only exception is for compost as in Guido Berlucchi is higher since 2017 and for Castello Bonomi in 2019 is similar to the test.

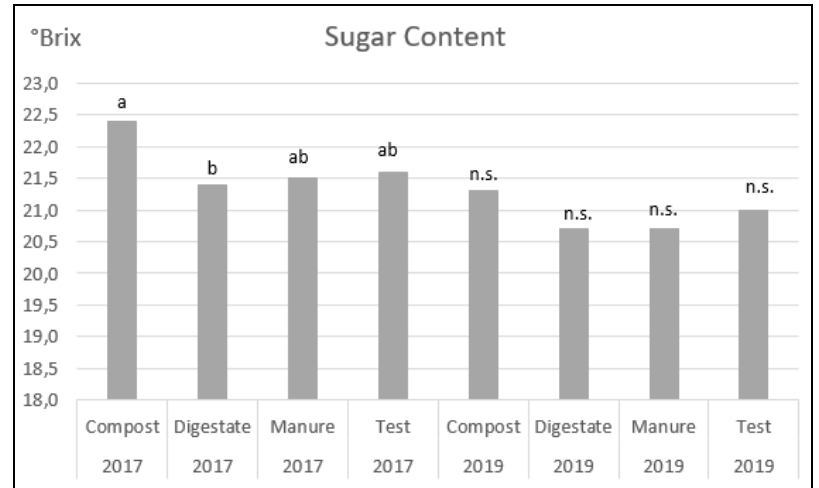

Fig.6. Sugar content comparing different type of fertilizers

Figure 6 shows results obtained for must sugar content; in 2017 a significance difference between compost and digestate treatments was recorded, while in 2019 no differences are shown among treatments. The effect of digestate on grape maturation seems to lead to an improvement in the acidic-sugar balance as reported for the value of sugar content in $2019[11,14,16]$.

No differences in $\mathrm{pH}$ are highlighted both for 2017 and 2019 (data not shown).

\subsection{Wine characterization}

Results obtained from wine tasting do not show similar responses for all wineries considered in the study. Identify possible influences of organic fertilization on wine sensory profiles is thus difficult; some results obtained are reported in Figure 7 and 8.

Figure 7 shows the different level of perception of green-vegetable aroma for Sangiovese of Premiata Fattoria Castelvecchi. The main level of this aroma is recognized for manure fertilizers, both in the tilled or not tilled treatment.

Differences recorded in wine structure for Cabernet sauvignon wines obtained from vineyard of Conti degli Azzoni winery are reported in Figure 8. Results suggest that the fertilizer application, with the exception for CL and DNL treatments, increased the structure of the wines for 2019 compared to 2017, while the control not treated shows a decreased in this wine characteristic.

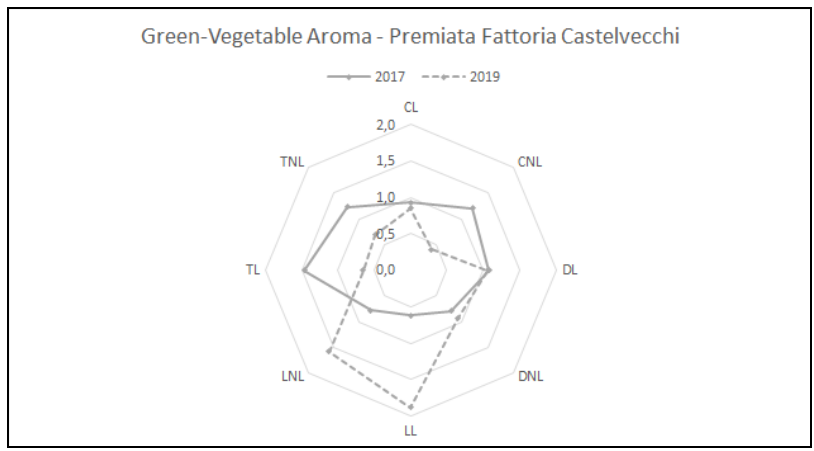

Fig.7. Green-Vegetable aroma found in wine obtained from vineyard of Premiata Fattoria Castelvecchi. $\mathrm{CL}=$ Compost incorporated into the soil; $\mathrm{CNL}=$ Compost not incorporated into the soil; $\mathrm{DL}=$ Solid fraction of digestate incorporated into the soil; DNL = Solid fraction of digestate not incorporated into the soil; $\mathrm{LL}=$ Manure incorporated into the soil; $\mathrm{LNL}=$ Manure not incorporated into the soil; $\mathrm{TL}=$ Test not fertilized and not tilled; TNL $=$ Test non fertilized but tilled.

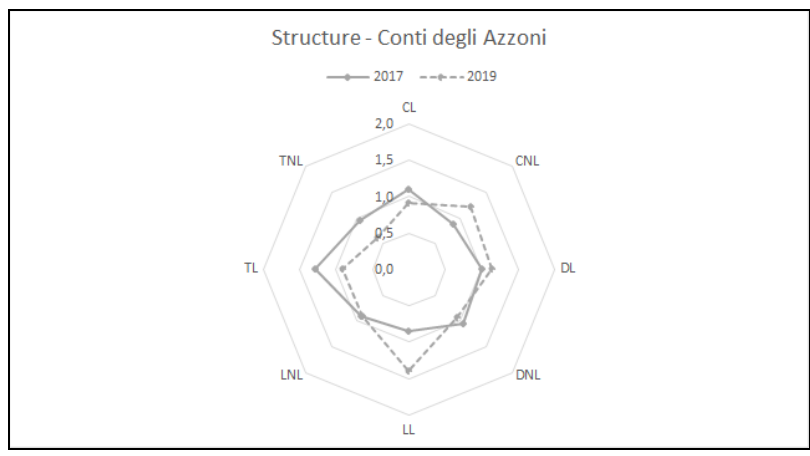

Fig.8. Wine structure described in wines obtained from vineyard of Conti degli Azzoni winery. $\mathrm{CL}=$ Compost incorporated into the soil; $\mathrm{CNL}=$ Compost not incorporated into the soil; $\mathrm{DL}=$ Solid fraction of digestate incorporated into the soil; DNL = Solid fraction of digestate not incorporated into the soil; $\mathrm{LL}=$ Manure incorporated into the soil; $\mathrm{LNL}=$ Manure not incorporated into the soil; $\mathrm{TL}=$ Test not fertilized and not tilled; TNL $=$ Test not fertilized but tilled

\section{Conclusions}

This study reports some interesting element to better understand the effect that SOM apported with different organic fertilizers can determine on the vines, musts and wines. Results obtained shows that the greatest effect is reflected on must acidic content which increases with the application of the organic fertilizers; the effects on wines are more heterogeneous and do not allow to find a generalized response. Further results are required to study effect of organic fertilization for more years, since the effects of SOM occur over a long-term period.

\section{References}

1. J. Delas, C. Molot and J.P. Soyer. International symposium on nitrogen in grapes and wine, 242-248 (1991) 
2. F. Lalatta. Estratto da L'Informatore Agrario, 1 (1971).

3. P. Sequi. Giornate frutticole, Economia Trentina, 3, 1723 (1980).

4. A. Scienza, L. Valenti. Supplemento a VigneVini, 6, 5772 (1983).

5. A. Vercesi. VigneVini, 9, 47-54 (1996).

6. R. Morlat. Am. J. Enol. Vitic., 59, 364 - 374 (2008).

7. A. Castaldi. Supplemento a L'Informatore Agrario, 6: 58 (2009).

8. M. Perelli. L'Informatore agrario, 2, 4-6 (1987).

9. A. Vez. Agriculture et environment - Revue suisse Agric., 19 (3), 135-142 (1987).

10. L. Valenti, P. Donna, I. Ghiglieno. L'Informatore Agrario, 5, 36-40 (2014).

11. S. Mugnai, E. Masi, E. Azzarello, S. Mancuso. Compost Science \& Utilization, 20 (1), 29-33 (2012).

12. G. Colugnati, G. Cattarossi, G. Crespan. L'Informatore Agrario, 10: 53-65 (2006).

13. L. Valenti, I. Ghiglieno, M. Bravi, M. Tonni, E. Mescalchin, R. Zanzotti, M. Secchi, L. Pecetti. L'Informatore Agrario, 26, 36-45 (2012).

14. S. E. Spayd, R. L. Wample, R. G. Evans, R. G. Stevens, B. J. Seymour, C. W. Nagel. Am J Enol Vitic. 45, 34-42 (1994)

15. C. Nendel, S. Reuter. Compost Science \& Utilization, $\mathbf{1 5}$ (2), 70-77 (2007).

16. L. P. Christensen, M. L. Bianchi, W. L. Peacock, D. J. Hirschfelt. Am J Enol Vitic. 45 (4), 377-387 (1994). 